\title{
A Comparison of Marital Satisfaction of Mothers Raising a Child with Intellectual Disability versus a Child with Autism Disorder in Bahrain: Mixed Method Study
}

\author{
Mariam E. Al-Shirawi \\ Associate Professor \\ Arabian Gulf University
}

Received: April 10, 2018 Accepted: May 24, 2018 Published: May 24, 2018

doi:10.5296/jse.v8i2.13100 URL: https://doi.org/10.5296/jse.v8i2.13100

\begin{abstract}
The purpose of the current mixed method study was to explore marital satisfaction of mothers raising children with Intellectual disability (I.D), or Autism disorder Children (A.D).The participants were thirty seven mothers, 21 of them had a child with autism disorder and 16 had a child with Intellectual disability. Twenty two of the mothers participated in the semi-structured interviews using the marital satisfaction questionnaire (MSQ) which is a self-report questionnaire prepared to assess marital satisfaction. The results reported $70 \%$ of the mothers had high level marital satisfaction. Results showed no significant difference in the level of marital satisfaction between mothers of children with (I.D) and mothers of children with (A.D). The regression analyses indicated that social support, significantly predicted mothers' marital satisfaction, while other variables (income, child birth order, gender of a child, age of a child, age of mother, age of husband, social support, marital years) were not found to be influential in predicting marital satisfaction. Qualitative thematic analysis showed that most of the mothers have a high level of marital satisfaction and received support from their husbands, their families and their mothers' in-law, as well as support from professional specialists like pediatricians, psychologists, special education teachers and some friends.
\end{abstract}

Keywords: mixed method, marital satisfaction, intellectual disability, autism disorder, social support, predictors 


\section{Introduction}

Families are faced with varying levels of stress related to having a developmentally disabled child. Marital satisfaction is the result of wives and husband's harmony and compatibility in all aspects of life that in turn supports the family's and parents' health. Parents' marital satisfaction protects life balance and it is essential for emotional status of the family.(Lohranpour and Chahartangi 2016).

Raising a child with a disability is an unexpected experience for parents. Mothers play a major role in childrearing, regardless of the presence or absence of a disability. (Yamaoka,2016) Mothers, and mothers of disabled children in particular, are the primary caretakers as they have the main responsibility for raising their child.(Stylianou,2017) Raising a child diagnosed with a developmental disability can contribute positively or negatively to the marital relationship of the parents.

Marital satisfaction is one of the protective factors for positive adaptation to stressful situations, such as the management of a disabled child. Higher levels of marital satisfaction are related to lower levels of depression, lower parenting stress, and improved efficiency in the parents' role (Kersh, Hedvat, Hauser-Cram, \& Warfield, 2006). Much of the research demonstrates that parents of disabled children and, specifically, those of developmentally disabled children, report lower levels of marital satisfaction when compared with couples of non-disabled children and with those of children with down syndrome (Higgins, Bailey, \& Pearce, 2005; Kersh et al., 2006).

\section{Theoretical Framework}

Parenting children with disabilities may influence the parents positively or negatively (Hock, Timm, \& Ramisch, 2012). The research on how a childhood disability influences marital relationship has yielded mixed results. Early studies investigating the impact of childhood disability on marital satisfaction conclude that couples with disabled children are more distressed than parents of those with normally developing children,(Hartley et al 2010).Several other studies report significantly lower levels of marital satisfaction in couples with disabled children (Floyd \& Zmich, 1991; Flodapp \& Krasner, 1995\& Gau 2011). These studies conclude that having a disabled child creates strain both on the marriage and on the family. Brobst, Clopton, and Hendrick (2009) contend that parents face the challenge of making time for their children as well as their partners. Some marriages have the potential to be positively affected when raising a child with a disability. The couple may have to work together to keep their marriage intact but they may be offered social support from other families in a similar situation. In addition, the couple may increase time spent with one another in order to cope with their child's condition by working together to assist their child. (Katangian2016).

Parenting a child with an autism spectrum disorder or a child with intellectual disability presents unique challenges, including assisting the child in navigating complex social relationships, transitioning out of school and into job and community settings, and planning for long-term care. The marital relationship may be a particularly important resource for 
dealing with these challenges. (Hartley et al.2010).

The marital relationship in parents of children with disabilities has been the focus of numerous research studies. For instance, Simmerman, Blacher, and Baker (2001), in a longitudinal study found that the father's involvement with raising children affected with disabilities, led to mother's satisfaction which in turn was associated with both parents' marital adjustment.

Many of these studies examined the impact of having a child with a disability on the marital relationship. Some studies have indicated that there is no difference in quality of the marital relationship between parents of children with a disability and parents of children without a disability, fathers in families of children with disabilities performed significantly fewer parenting duties than did their spouses or fathers in the non-disabled group. (Hartley et al. 2010) - couples with an autistic child were twice as likely to divorce; the divorce rate after five years was $26 \%$ vs. $13 \%$ in the general population. Freedman et al. (2012) study of nearly 78,000 parents found no significant difference in rates of separation. Several studies have found lower levels of marital satisfaction, Mothers of autistic children reporting more stress and less marital satisfaction than did fathers. (Gau 2011). Urbano (2007) found that parents of children with Down syndrome actually had a lower rate of divorce than the married couple of other birth defects and those of no identified disability. Most common stressors reported in this group were related to the child's health and physical limitations rather than behavior (Dabrowska, 2010). Children with Down syndrome are typically easier to raise than those with other intellectual and developmental disabilities, and parents often report less stress and higher life satisfaction. Parents of children with (ASD) reported lower levels of marital satisfaction than did both parents of typically developing children and parents of children with other disabilities. (Dunn et al. 2001).

Parents of children with developmental disabilities (DD), including intellectual disability (ID), are at elevated risk for marital distress and dysfunction compared to parents of typically developing children, as indicated by self-reported measures of marital satisfaction. This is especially troubling in that even when the mother was employed full-time, she still undertook the bulk of the parenting responsibilities, parents of children with disabilities scored higher on measures of depression than did parents of typically developing children(Elizabeth \& Vogt, 2007),(Bristol, Gallagher, \& Schopler, 1988), (Friedrich \& Friedrich, 1981),(Floyd \& Zmich, 1991).

Parents of children with DD may also be at greater risk for divorce (Hartley et al., 2010; Hodapp \& Krasner, 1994). For example, Hartley et al., (2010) compared divorce rates in parents of neurotypical children and parents of children with autism spectrum disorder (ASD), and found not only that the rate of divorce was higher overall in the(ASD) group, but also that the risk of divorce that is typically the highest in the earlier years of marriage was protracted for these couples (Cohen, 2015).

Several studies have also examined the child characteristics (behavior problems) related to high- versus low- quality marital relationships (Baker, Blacher, \& Olsson, 2005); (Simmerman, Blacher, \& Baker, 2001). Findings from (Brobst et al.'s 2009) study suggest 
that increased child behavior problems not only contribute to increased maternal stress, but also lower levels of marital satisfaction and spousal support for the mothers.

Although Risdal and Singer's (2004) meta-analysis study revealed an overall adverse effect of having a child with a developmental disability on marital satisfaction across studies, some of the studies showed equal or even better marital adjustment in a disability sample than in a sample without disability. More recently, Daire, Munion, and Carlson (2011) compared the marital satisfaction of parents of children with and without disability and found no significant differences.

Having a child with disability, especially with severe autism, places an increased amount of stress on marital satisfaction, often leading to depression in the parents (Hwang \& Olsson,2001). When parents of children with autism become depressed, they often feel guilty (Kuhn \&Carter, 2006) and lose confidence in their ability to adequately care for their children (Meirsschaut, Roeyers, \& Warreyn, 2010). In addition, parental stress is often a source of marital conflict (Kelly,2008). Research has also shown that marital conflict can lead to more severe symptomatology among children with autism (Kelly, Garnett, Attwood, \& Petterson, 2008).

(Abbas \& chahartangi, 2016)study found that there is no significant difference in marital satisfaction between mothers with exceptional children in caring centers and mothers with normal children.

A study of marital satisfaction in parents with children of mental disability used a descriptive-analysis with category-random method and indicated that parents of children with mental disability are in unfavorable condition in regard to marital satisfaction. (Mikaeli \& Niloofar, 2012).

Marital satisfaction of parents with normal students and students with mental disability was studied in West Azerbaijan and the results indicated that marital satisfaction in parents of children with mental disability is less than marital satisfaction of parents of normal children. (Abbas \&chahartangi, 2016)

\section{Purpose of the Study}

The purpose of this concurrent mixed methods study was to assess the impact of raising a child with a disability on mothers' marital satisfaction. Also, this study compares marital Satisfaction of mothers of a child with an intellectual disability to those of mothers with autistic children.

\section{Quantitative Research Question}

The following major research question were addressed in this study:

1. Does the presence of a child with a developmental disability influence the mothers' marital satisfaction level?

2. Do mothers who have an intellectual disability child differ significantly in marital satisfaction from mothers who have an autistic child? 


\section{Macrothink}

3. What variables (e.g., income, child birth order, gender of a child, age of a child, and age of mother, age of husband, social support, and years of marriage) are the most significant predictors of marital satisfaction of mothers of children with disabilities?

\section{Method}

\section{Research Design}

The study adopted a sequential mixed methods design which involved a phase of quantitative survey interviews $(n=37)$ followed by a qualitative phase on a subsample $(n=22)$ purposely drawn from the survey respondents in order to explore marital satisfaction in mothers who have an Intellectual disability child and mothers who have an autistic child.

Structured questionnaires and semi-structured interviews are often used in mixed method studies to generate confirmatory results despite differences in methods of data collection, analysis, and interpretation. One of the advantages of using mixed methods design is to facilitate a better understanding of the research problem. A mixed methods approach to the research provided us with more comprehensive evidence for this study than either a quantitative or a qualitative approach alone(Creswell \& Clark, 2011).

The Marital Satisfaction Questionnaire was used to collect quantitative data.

A qualitative approach, using semi-structured interviews as the method of data collection, would be the most useful to reach an open dialogue with participants, that is mothers who have an intellectual disability child and mothers who have an autistic child. Such an approach allows the participants degrees of freedom when answering questions.

\section{Participants}

The participants were thirty seven mothers, 21 of them had a child with autism disorder and 16 had a child with Intellectual disability and 22 of mothers participated in the interviews. (Mothers average age $=39.18 \pm 10.7$ ). the participants were selected from the same population. All mothers belonged to a middle socio-cultural level $(65 \%$ of mothers had a secondary school level, $35 \%$ of mothers had a university degree). Most of the mothers were housewives (87\%), while13\% worked in public administration. 
Table 1. Percentage distribution of socio-demographic characteristics of mothers with a child with a disability

\begin{tabular}{lcc}
\hline Respondents & $\mathrm{N}$ & $\%$ \\
\hline Mothers & 37 & 100
\end{tabular}

Age( years)

$18-29$

$30-39$

40 and above

Marital status

Married

Divorced/Separated

Education Level

High School

Diploma

University degree

Family Size

1 to 5 children

More than 5 children

Total

\section{Instruments}

\section{Demographic Questionnaire}

1. The demographic questionnaire contains questions regarding age, gender, marital status, number of children, employment status, socioeconomic status, and education level.

The Marital satisfaction Questionnaire (MSQ) was a self-report measure that was designed to 
assess marital satisfaction of mothers. This instrument consisted oftwo subscales that included 52 items; first the Marital Satisfaction Subscale which included 41 items and the second Social Support subscale which included 11 items. All the items were rated on a 5 point Likert scale $(0=$ strongly disagree to $5=$ strongly agree $)$ The (MSQ) internal consistency of the Marital Satisfaction Scale for the present sample was $\alpha=.88$ The internal consistency of social support domain $\alpha=.78$ and total scale was $\alpha=.93$ indicating high internal reliability and validity investigated by Concurrent validity: Concurrent validity applies to validation studies in which the two measures are administered at approximately the same time. This study used the Marital Adjustment Questionnaire (MAQ) constructed and standardized by Pramod Kumar and. Kanchana Rohatgi (1999) The concurrent validity between MSQ and (MAQ)was $(r=0.87)$ indicating high validity.

\section{Interviews}

The interviews (face-to-face) were agreed upon with the participants. The interview started by explaining to the mother that she is here to share her story with her partner. Interviews were written after obtaining permission from the mothers and assuring them that the recorded data would only be used for research purposes. Data were gathered using semi-structured face-to-face interviews carried out by the researcher, and questions during the interview covered the key points of the research questions. During the interviews, mothers were encouraged to speak freely about their experiences, what they believed was important, and how they reacted to these experiences. Different types of questions were used during the interviews such as direct questions, for instance:

Q1: How did you know each other before marriage?

Q2: What are the bases on which you chose your partner?

Q3: Have all or part of these bases that have been discussed earlier are available?

Q4: How do you describe your relationship with your partner during that period?

Were there positive and negative aspects?

Q5: Was your life happy? If there were some problems I request you to describe this stage accurately, if you wish to do so.

Q6: In the first period of diagnosis did any change happen in your relationship with your partner?

Q7: what negative or positive changes occurred and whether the reactions varied after that. Please describe this stage accurately, in detail, if you wish.

Q8: What sources of support have you received, whether material, social or emotional, from those around you?

Q9: Can you assess your satisfaction with your marital relationship, is it excellent, good, medium or weak? 


\section{Procedure}

Research ethics were maintained throughout the research, a list of various centers of special education in Bahrain was generated for the purpose of selecting the sample of the study. Permission was sought from the heads of relevant centers to collect the data. Letters asking mothers to participate were sent home with children who attended the centers. The letter asked the mothers who wished to participate to call the researcher in order to arrange interviews (face-to-face). Interviews were written after obtaining permission from the mothers and assuring them that the recorded data would only be used for research purposes.

\section{Data analysis}

A sequential mixed methods design which involved a phase of quantitative survey interviews $(n=37)$ was followed by a qualitative phase on a subsample $(n=23)$.

The Statistical Package for Social Science (SPSS) was used to verify the hypotheses. Non-parametric statistics were used to analyze data. To analyze possible differences between mothers of children with autism and mothers of children with intellectual disability, Mann-Whitney (U) test) was applied in order to verify statistical differences.

\section{Results}

Q1: Does the presence of a child with a developmental disability influence the mothers' marital satisfaction level?

Marital Satisfaction on a scale from 1 - 5, the level of marital satisfaction was considered as relatively high $(\mathrm{M}=3.8, \mathrm{SD}=0.77)$. Seventy percent of mothers were above mid-point that means the majority of mothers in this study had high levels of marital satisfaction.

Q2: Do mothers who have an intellectual disability child differ significantly in marital satisfaction from mothers who have an autistic child?

\section{Differences between groups}

Means and Standard Deviations of the (MSQ) scores of mothers of disabled (Autism and Intellectual disability children) as shown in Table 2

Table 2. Means and Standard Deviations of the (MSQ) scores of mothers of disabled (Autism and Intellectual disability children)

\begin{tabular}{lccc}
\hline Mothers of children with & $\mathrm{N}$ & Mean & $\mathrm{SD}$ \\
\hline autism & 21 & 161 & 26.88 \\
Intellectual disability & 16 & 151 & 37.38 \\
\hline
\end{tabular}

Table 3 indicates no statistical differences were found when comparing total (MSQ) scores of mothers of children with autism with mothers of children with Intellectual disability as shown in Table 3. $[U=161.5 ; Z=-0.199 ; p=.84]$. 
Table 3. Non-parametric statistics Mann-Whitney (U) test for mothers of children with autism with mothers of children with intellectual disability

Mothers of children with $\quad$ Mean Rank $\quad$ Sum of Ranks $\quad U \quad Z \quad Z \quad P$

(One-tailed)

\begin{tabular}{lccccc}
\hline autism & 19.31 & 405.50 & 161.5 & -0.199 & 0.84 \\
Intellectual disability & 18.59 & 297.50 & & & \\
\hline
\end{tabular}

U- Mann-Whitney test, Z- z test \& P- probability

Q3: What variables (e.g., income, child birth order, gender of a child, age of a child, and age of mother, age of husband, social support, and years of marriage) are the most significant predictors of marital satisfaction of mothers of children with disabilities?

To assess the predictors, linear regression analysis was used to examine the effects of eight sources of marital satisfaction. The results showed that the model explained $26 \%$ of the variance in marital satisfaction $(\mathrm{R} 2=.27, \mathrm{~F}(1,34)=4.79, p<.001)$. Only social support $(\beta=$ $2,85, p<.001)$ was found to be a significant predictor of marital satisfaction of mothers of children with mental disabilities. Table 4 shows that the seven variables(income, child birth order, gender of a child, age of a child, age of mother, age of husband, years of marriage ) were not found to be influential in predicting marital satisfaction of mothers of children with disabilities.

Table 4. Step-Wise Regression Analysis for Predicting Marital satisfaction $(\mathrm{N}=$ 37).indicating that the social support were more high correlated coefficients with marital satisfaction as it had a significant positive regression weight, $\beta=0.52, t(3.47), \mathrm{p}<.001$, indicating marital satisfaction can be predicted better by social support than other predictors which are income, child birth order, gender of a child, age of a child, age of mother, age of husband and years of marriage . 


$\begin{array}{llllll}\text { Model } & B & S E & \beta & T & P \\ \text { SOCIAL_SUPORT } & 2.85 & 0.76 & 0.52 & 3.47 & 0.001\end{array}$

\section{B- Unstandardized regression coefficient}

\section{SE- Standard error}

\section{$\beta$ - Standardized regression coefficient}

\section{T- T test}

\section{p- Significant level}

\section{Qualitative Results}

Mothers of Intellectual Disability Children (I.D.C) and mothers of Autistic Children (A.C) were interviewed using a questionnaire that consisted of three questions. Following is a report of the results of the interviews with the mothers.

The total number of the mothers was twenty two; eleven mothers of (I.D.C), and eleven mothers of (A.C).

The first question related to how the parents met each other, the character traits that the mother considered desirable in taking the marriage decision, whether these were present in her husband, and the kind of relationship they had before the birth of their disabled child.

Five mothers of (A.C) were married the traditional way (arranged) through relatives or friends, four married their husbands after a love affair, and two met their husbands on the internet. Seven mothers of (I.D.C) had traditional marriages (arranged) through friends or relatives, while four mothers met their husbands and had a love affair with them before marriage.

Regarding the second part of the first question that dealt with the husbands' traits; most of the women interviewed responded that their husbands have the desired traits, with the exception of two mothers of (I.D.C); the first one had a traditional marriage through a relative and found out that her husband had mild development delays. The other one said that her husband had all the desirable traits during their engagement, but after marriage she found him to be a totally different man.

Regarding the third part of the first question relating to quality of the marriage relationship before having the disabled child; most mothers of both groups of children reported that they had a close, pleasant and positive marriage relationship (even perfect for some), except one mother of an autistic child who married traditionally. She described the marriage relationship as very bad, unhappy and negative from the very beginning; to the degree that she experienced insults that she can't forget even though she has been divorced for twenty three years. 
Similarly, a mother of a child with moderate intellectual disability described her relationship with her husband as very negative and ended in her filing for divorce after twenty years of suffering in an abusive relationship.

In answering the second question about who informed the family about their child disability; most of the mothers of (I.D.C) found out through the pediatrics section of the medical centers they visited; except one mother who discovered her daughter's disability because her development differed from her older sisters', and another case that was discovered by the kindergarten teacher.

For the (I.D.C) cases, the mothers were informed by the pediatric section at the maternity hospital. In the case of the (A.C), the mothers found out from the psychiatrist after referral of a number of cases by the elementary school, or by kindergarten teachers, except two mothers who noticed that their children's sleep, eating behaviors and eye contact were not normal. What they noticed was confirmed by a pediatric specialist who referred them to a psychiatrist

In the second part of the second question about the family's reaction after having been informed of their child's special needs; all the mothers went through shock, denial, deep sadness, self-blame and blaming the doctors. The period between being advised of the special need of the child and acceptance of this fact varied, due to many factors; including the husband's support for his wife. Mothers who passed quickly through the shock and denial stages were those mothers who received support from their husbands, their in-laws, some friends and specialist professionals. While six mothers of (I.D.C) confirmed that respect, intimacy, understanding, and cooperation between them and their spouses increased after the diagnosis of their child case, two mothers said that in their case there was separation then divorce. Four mothers mentioned that they didn't experience any change in their relationship with their husbands and that it stayed normal, as it used to be. One mother of an (I.D.C) reported that her husband was more emotionally affected than her, and he became more attached to his family to the extent that he abandoned some of his athletic and business commitments in order to spend longer times with his wife and their child, which caused the mother to feel jealous of the father's attachment to the daughter, and the excessive attention given to the daughter by the mother's and the father's family. For this reason, the mother explained to both families that her child must take on some responsibility in order to prepare her to lead an independent life. The mother was successful in doing this, as she reported that her child is now twelve years old, but has acquired more life skills than her friends had at her institution. This mother also prepared the child's brothers and sisters to take on part of the responsibility of taking care of their (DSC) in order to secure the child's future, after the death of one of the parents.

In summary, reactions varied between shocks, denial, self-blame, and blaming doctors. After this stage, most of the families led a normal positive life. Contrary to expectations, seven families out of twenty two families reported experiencing a better and more intimate marital relationship, as the families took precautions in order to prevent having further children, which may lead to another special needs child. Some families expended effort to better educate themselves through enrolling in special training and workshops organized by 
specialized centers and societies in the field of intellectual disabilities and autism. In six of the study sample cases, the husband was the main source of support for the wife and the special needs child.

The third question regarding support resources:

In most of the study cases the mothers received support from their husbands, their families and their in-laws, with the exception of four cases; two fathers of (I.D.C), and two fathers of (A.C) left their wives to handle the situation alone.

Most of the mothers received support from professional specialists like pediatricians, psychologists, special education teachers and some friends.

The fourth question regarding the mother's evaluation and the extent of her satisfaction with her marital relationship:

The mothers' rated their marital relationship between excellent to good, except four cases; two cases were divorced, in one case the husband married another woman; and in one the husband abandoned his wife.

Summary of interviews results:

1. $75 \%$ of the mothers had a high marital satisfaction rate, $20 \%$ mothers had a good marital satisfaction level, while only $5 \%$ of the mothers did not have a satisfactory marital level.

2. The study interviews were an opportunity for some mothers to become aware of available professional societal support resources.

3. The interviews with the mothers contributed towards identifying some of the mothers' needs, although it wasn't within the purposes of the study to help the mothers. Engagement and familiarity of the mothers with the researcher was an opportunity to identify mothers' needs, like the dire need of some of the (I.D.C) for speech therapists (in six mothers out of eleven).

4. There is a need to train teachers of Al-Amal institute for Special education in the field of behavior modification. There was a very high need for behavior modification in six cases. Teachers did not have any experience in that area. For the autism cases, there was a need for training the mothers in methods for behavior modification and oral communication.

5. Communication with the parents was a key to obtaining the results. The researcher conducted a workshop in behavior modification for teachers at Al-Amal Institute for Special education. The researcher also introduced the board of the Bahrain Society for mental Retardation and Autism to the idea of autistic children participation in horseback riding, as a way to train them to communicate in a natural environment. The researcher has had positive experience in this field, through her involvement with a group of autistic children enrolled in the Bahrain Society for Intellectual Disability. The study results were positive and the implemented program contributed to increasing communication and social interaction skills of the study sample cases. 


\section{Discussion}

The purpose of the current mixed methods study was to explore the influence of having an Intellectual Disability child (I.D) and an Autism Disorder Child (A.D) on the mothers' marital satisfaction level, and to explore the differences in marital satisfaction when comparing mothers of children with autism with mothers of children with Intellectual disability in Marital Satisfaction, and determine the variable influential in predicting Marital satisfaction using a mixed-methods approach. The results showed that $70 \%$ of mothers had a high level of marital satisfaction. The rest of the sample (30\%), who didn't have marital satisfaction were either separated or divorced without any source of support. The results supported the hypothesis that there were no significant differences in marital satisfaction between mothers of children with autism and mothers of children with Intellectual disability. The quantitative regression analyses indicated that social support, significantly predicted mothers marital satisfaction, while other variables (income, child birth order, gender of a child, age of a child, age of mother, age of husband, social support, years of marriage) were not found to be influential in predicting marital satisfaction. The quantitative data support the qualitative data and provided a deeper exploration regarding the mothers' marital satisfaction.

Research on marital satisfaction of Arab Muslim couples has been rare as Muslim culture considers marital satisfaction a private matter between husband and wife rather than an issue that can be comfortably subject to open discussion. Research has found cultural differences in the differentiation of good and bad marriages. Read (2003) found that acculturation decreased traditionalism in gender role beliefs, and noted that that $79.8 \%$ of her sample of 182 Muslim Arab-American women opposed letting their husbands make all the major family decisions (Ahmad\& Reid, 2016).The social support the extended family in the Arab Muslim society provided, reduced the need for the husband and wife to depend on each other for companionship needs (Ahmad \& Reid,2008). Satisfaction is likely to vary across cultures. The Western pattern is that egalitarian power distribution has the most positive impact on marital satisfaction (Amato, Johnson, Booth, \& Rogers, 2003).

\section{Conclusion}

According to the results obtained from this study we can conclude that social support is the most important factor in marital satisfaction of mothers of ID or AD children. The majority of the sample of this study (70\%) had a high marital satisfaction regardless of having an (ID) child or an (AD) child. The rest of the sample, (30\%) of the mothers who didn't have marital satisfaction were either separated or divorced, and without any source of support.

The researcher recommends doing further research on needs of mothers of special needs children, and types of specific social support to help parents of these children in achieving high marital satisfaction.

\section{References}

Abbas, G., \&chahartangi, s. (2016). Comparative Analysis of Marital Satisfaction and Quality of life in Mothers with Exceptional Children and Mothers with Normal Children. International Journal Of Medical Research \& Health Sciences. 
Ahmad, S., \& Reid, D. (2008). Relationship Satisfaction among South Asian Canadians: The Role of 'Complementary-Equality' and Listening to Understand. Interpersona: An International Journal On Personal Relationships, 2(2), 131-150. https://doi.org/10.5964/ijpr.v2i2.23

Ahmad, S., \& Reid, D. (2016). Enhancing the Relationship Adjustment of South Asian Canadian Couples Using a Systemic-Constructivist Approach to Couple Therapy. Journal Of Marital And Family Therapy, 42(4), 615-629. https://doi.org/10.1111/jmft.12161

Amato, P., Johnson, D., Booth, A., \& Rogers, S. (2003). Continuity and Change in Marital Quality Between 1980 and 2000. Journal Of Marriage And Family, 65(1), 1-22. https://doi.org/10.1111/j.1741-3737.2003.00001.x

Antigoni, S. (2017). Mothers with disabled children in Cyprus: experiences and support. Unpublished doctoral dissertation, Institute of Education University of London. http://discovery.ucl.ac.uk/10023393/1/Stylianou_10023393_Thesis.pdf

Baker, B., Blacher, J., \& Olsson, M. (2005). Preschool children with and without developmental delay: behaviour problems, parents' optimism and well-being. Journal Of Intellectual Disability Research, 49(8), 575-590. https://doi.org/10.1111/j.1365-2788.2005.00691.x

Brobst, J. B., Clopton, J. R., \&Hendrick, S. S. (2009). Parenting children with autism spectrum disorders: The couple's relationship. Focus on Autism and Other Developmental Disabilities, 24, 38-49. https://doi.org/10.1177/1088357608323699

Creswell, J. W., \& Plano Clark, V. L. (2011). Designing and conducting mixed methods research (2nd ed.). Thousand Oaks, CA: Sage Publications, Inc.

Daire, A., Munyon, M., Carlson, R., Kimemia, M., \&Mitcham, M. (2011). Examining Distress of Parents of Children With and Without Special Needs. Journal Of Mental Health Counseling, 33(2), 177-188. https://doi.org/10.17744/mehc.33.2.qu73p03176337xx1

Dunn, M. E., Burbine, T., Bowers, C. A., \&Tantleff-Dunn, S. (2001). Moderators of stress in parents of children with autism. Community Mental Health Journal, 37, 39-53. https://doi.org/10.1023/A:1026592305436

Floyd, F., \& Gallagher, E. (1997). Parental Stress, Care Demands, and Use of Support Services for School-Age Children with Disabilities and Behavior Problems. Family Relations, 46(4), 359. https://doi.org/10.2307/585096

Floyd, F., \& Zmich, D. (1991). Marriage and the Parenting Partnership: Perceptions and Interactions of Parents with Mentally Retarded and Typically Developing Children. Child Development, 62(6), 1434. https://doi.org/10.2307/1130817

Freedman, B., Kalb, L., Zablotsky, B., \& Stuart, E. (2012). Relationship status among parents of children with autism spectrum disorders: A population-based study. Journal of Autism and Developmental Disorders, 42(4), 539-548. https://doi.org/10.1007/s10803-011-1269-y 
Gau, S. S., Chou, M., Chiang, H., Lee, J., Wong, C., Chou, W., \& Wu, Y. (2012). Parental adjustment, marital relationship, and family function in families of children with autism. $\begin{array}{llll}\text { Research in Autism Spectrum } & \text { 263-270. }\end{array}$ https://doi.org/10.1016/j.rasd.2011.05.007

Gray, D. (1997). High functioning autistic children and the construction of "normal family life". Social Science \& Medicine, 44(8), 1097-1106. https://doi.org/10.1016/S0277-9536(96)00237-7

Hanson, W., Creswell, J., Clark, V., Petska, K., \& Creswell, J. (2005). Mixed methods research designs in counseling psychology. Journal Of Counseling Psychology, 52(2), 224-235. https://doi.org/10.1037/0022-0167.52.2.224

Harris \& Brown. (2010). Mixing interview \& questionnaire methods. Practical Assessment, Research \& Evaluation, 15(1), 2.

Hartley, S., Barker, E., Seltzer, M., Floyd, F., Greenberg, J., Orsmond, G., \& Bolt, D. (2010). The relative risk and timing of divorce in families of children with an autism spectrum disorder. Journal Of Family Psychology, 24(4), 449-457. https://doi.org/10.1037/a0019847

Hartley, S., Barker, E., Seltzer, M., Greenberg, J., \& Floyd, F. (2011). Marital Satisfaction and Parenting Experiences of Mothers and Fathers of Adolescents and Adults With Autism. American Journal On Intellectual And Developmental Disabilities, 116(1), 81-95. https://doi.org/10.1352/1944-7558-116.1.81

Higgins, D., Bailey, S., \& Pearce, J. (2005). Factors associated with functioning style and coping strategies of families with a child with an autism spectrum disorder. Autism, 9(2), 125-137. https://doi.org/10.1177/1362361305051403

Hock, R., Timm, T., \& Ramisch, J. (2011). Parenting children with autism spectrum disorders: a crucible for couple relationships. Child \& Family Social Work, 17(4), 406-415. https://doi.org/10.1111/j.1365-2206.2011.00794.x

Kelly, A. B., Garnett, M. S., Attwood, T., \& Peterson, C. (2008). Autism spectrum symptomatology in children: The impact of family and peer relationships. Journal of Abnormal Child Psychology: An Official Publication of the International Society for Research in Child and Adolescent Psychopathology, 36(7), 1069-1081.

Kersh, J., Hedvat, T., Hauser-Cram, P., \& Warfield, M. (2006). The contribution of marital quality to the well-being of parents of children with developmental disabilities. Journal Of Intellectual Disability Research, 50(12), 883-893. https://doi.org/10.1111/j.1365-2788.2006.00906.x

Kuhn, J., \& Carter, A. (2006). Maternal self-efficacy and associated parenting cognitions among mothers of children with autism. American Journal Of Orthopsychiatry, 76(4), 564-575. https://doi.org/10.1037/0002-9432.76.4.564

Meirsschaut, M., Roeyers, H., \&Warreyn, P. (2010). Parenting in families with a child with autism spectrum disorder and a typically developing child: Mothers' experiences and 
cognitions. Research in Autism Spectrum Disorders, 4(4), 661-669. https://doi.org/10.1016/j.rasd.2010.01.002

Mikaeli, Niloofar (2012), Comparing Tolerance-Marital Satisfaction, Mental Health in Parents with Children having Educational Disability and normal Children.

Olsson, M., \& Hwang, C. (2001). Depression in mothers and fathers of children with intellectual disability. Journal Of Intellectual Disability Research, 45(6), 535-543. https://doi.org/10.1046/j.1365-2788.2001.00372.x

Pramod Kumar and Km KanchanaRohatgi (1999) .Marital adjustment questionnaire" constructed and standardized.

Raquel D. Katangian(2016)The Influence of Raising a Child with Autism on Marital Satisfaction A Dissertation Submitted to the Faculty of The Chicago School of Professional Psychology.

Read, J. (2003). The Sources of Gender Role Attitudes among Christian and Muslim Arab-American Women. Sociology Of Religion, 64(2), 207. https://doi.org/10.2307/3712371

Risdal, D., \& Singer, G. (2004). Marital Adjustment in Parents of Children with Disabilities: A Historical Review and Meta-Analysis. Research And Practice For Persons With Severe Disabilities, 29(2), 95-103. https://doi.org/10.2511/rpsd.29.2.95

Simmerman, S., Blacher, J., \& Baker, B. (2001). Fathers' and mothers' perceptions of father involvement in families with young children with a disability. Journal Of Intellectual \& Developmental Disability, 26(4), 325-338. https://doi.org/10.1080/13668250120087335

Urbano, R., \&Hodapp, R. (2007). Divorce in Families of Children With Down Syndrome: A Population-Based Study. American Journal On Mental Retardation, 112(4), 261. https://doi.org/10.1352/0895-8017(2007)112[261:DIFOCW]2.0.CO;2

Yamaoka, Y., Tamiya, N., Izumida, N., Kawamura, A., Takahashi, H., \& Noguchi, H. (2016). The relationship between raising a child with a disability and the mental health of mothers compared to raising a child without disability in japan SSM - Population Health, 2, 542-548. 